\title{
Problems of Portuguese science
}

SIR-As a Portuguese scientist working for twelve years in West Germany and associated with the academic society of Portugal for five, I read the survey on Science in Iberia (Nature 324, 313-332; 1986) with amusement: your journal has been used very effectively for the international airing of proposed programmes of the Portuguese Ministry of Education and its institutions. Whether these programmes will ever become a reality only time will tell.

I do not wish to question the good intentions of those concerned, but their effectiveness. This government has been in office for over a year. The real problems of science in Portugal are: (1) the legal structure of its institutions and their hiring policy (people are rarely fired) and (2) the attitudes and scientific competence of the majority of people in these institutions.

The first problem concerns the ministry and its power to introduce reforms. Why, for example, do teaching assistants with the equivalent of a master's degree effectively have tenure and a guaranteed permanence in the educational system? Why is there so much inbreeding in Portuguese educational institutions? Why are acadmic positions in Portuguese institutions almost never advertised in the international scientific press, where they would be brought to the attention of interested and qualified Portuguese living abroad? Why is it possible for Portuguese academics to have more than one job?

The second problem has historical roots which have both affected the Portuguese attitude towards science and the world and filled the Portuguese institutions with an astonishing number of incompetent people. It is well known that any multistep process, such as an educational or scientific establishment, is only as efficient as its least efficient step. There are some excellent and internationally competitive people and research groups in Portugal, but they are relatively few. Progress is, more often than not, hindered by the almost uncountably large number of dogin-the-manger types who still prevent the opening of Portuguese scientific culture to the rest of the world. This is partly because they feel intimidated by science at a modern international level and partly because they no longer speak the same language. Admittedly, the Ministry of Education is not directly to blame, but some initiative for change should, nevertheless, come from there. Why, for instance, is there no legislation enforcing a periodic evaluation of scientific and teaching competence of

Letters submitted for Correspondence should be typed, double-spaced, on one side of the paper only.
Portuguese scientists and professors as there is in almost every other progressive country? Why is demonstrated excellence never materially rewarded? Why are students in Portuguese universities never asked to evaluate course or entire degree programmes offered to them?

Finally, some specific comments regarding statements in your survey: Every Portuguese is very used to hearing catchy terms like "new blood" (p. 332), which makes it all the more difficult to understand why inbreeding is still a way of life in Portuguese institutions of higher education. "Patience" (p. 330) with all officialdom in Portugal is a necessary requisite for survival in that country. It is not the authorities that require this commodity.

Max-Planck-Institut WINCHIL L. C. VAZ

für Biophysikalische Chemie, Abt. Molekulare Biologie, Postfach 2841,

D-3400 Goettingen, FRG

\section{Citation counts}

SIR-The recently reopened debate about citation counts (Nature 324, 95; 1986 and 325,$478 ; 1987$ ) has highlighted the fact that we still do not know enough about citation behaviour to endorse the use of such analysis without qualification in matters of resource allocation. The technique aims at quantifying the impact of published research, this being one measure of the research output of university departments. Output should not, and cannot meaningfully, be considered in isolation from input, however.

A recent study conducted at Lancaster has investigated the determinants of research output in departments of economics in 40 British universities. A bibliometric measure of output per staff member (call it $X_{1}$ ) was constructed for the years $1980-84$. This was expressed as a function of university and department size, staff age, staff-student ratio, library stock, external funding and numbers of professors and research students. More than 70 per cent of the variation in $X_{1}$ can be explained in this way. The regression residuals - which represent that part of output that cannot be explained by differences in the inputs defined above - could themselves conceivably be used as a performance indicator. Call this latter measure $X_{2}$.

The Spearman's rank correlation coefficient obtained by comparing $X_{1}$ and $X_{2}$ is -0.597 . This indicates no significant degree of positive correlation between the two measures. If this is the case for economics, one shudders to think at how misleading citation counts might be for sciences where resource costs are greater.
Presumably the aim of performance indicators is to estimate value added. Citation counts alone are quite incapable of doing this. Even if bibliometric analysis could crudely reflect research output, they alone could never measure productivity.

Geraint Johnes

Department of Economics,

Gillow House,

University of Lancaster,

Lancaster LA1 $4 Y X, U K$

\section{New Zealand denial}

SIR-In an article "Genetic manipulation living outside regulation" (Nature 324, $202 ; 1986)$, it is stated that a team from Oregon State University in Corvallis had field-tested a modified vaccinia virus in sheep, cattle and chickens in New Zealand. The facts are that a scientist from Oregon State University came to New Zealand and requested permission for a field test of the vaccinia/sindbis oganism, but this request was denied. After consideration of the request and careful examination of the experimental protocol by the Wallaceville Animal Research Centre Biological Society Committee, in consultation with the New Zealand Advisory Committee on Novel Genetic Techniques, tests were allowed in calves and chickens under strict quarantine. No field trials were permitted and as far as I am aware there have so far been no field trials of any genetically engineered organisms in New Zealand.

Wallaceville Animal Research Centre,

J.N. PARLE

Private Bag,

Upper Hutt, New Zealand

\section{University rows}

SIR-I read with interest your opinion on professional athleticism at Oxford (Nature 325, 470, 1987).

The boat race between the eights of the Universities of Pavia and Pisa takes place each year alternately on the waters of the Ticino and of the Arno, the rivers flowing through the two old university towns. The rule that the rowing men must be students has in the past caused a hiatus of some years in the annual event when the presence in both crews of oarsmen who would not know what the social sciences were was considered too much, even given the Italian genius for compromise.

We did not at the time indulge in the luxury of brooding on such trivial matters but the survival of the two universities was then as always threatened by lack of funds. The University of Oxford is to be envied for being able to enjoy such luxuries when short of funds.

Collegio Fratelli Cairoli

Marco Fraccaro

Universita di Pavia

27100 Pavia, Italy 